\title{
Bacterial Survival in Suspension in Polyethylene Glycol Solutions
}

\author{
By C. S. COX \\ Microbiological Research Establishment, Porton Down, near Salisbury, \\ Wiltshire
}

(Received 4 January 1966)

\section{SUMMARY}

The \% survivals of Escherichia coli (в, Jepp, commune), Serratia marcescens (UK 8) and Aerobacter aerogenes (Hinshelwood), in the presence of polyethylene glycol were studied as a function of molecular weight and $\%$ polyethylene glycol. Polyethylene glycol is shown to cause a loss of viability; experiments are described which suggest loci for its action.

\section{INTRODUCTION}

During an investigation of the protective action of solutes on the survival of bacteria as aerosols it was observed that polyethylene glycol (PEG) was toxic (Cox, 1965). The present paper reports in vitro experiments which were designed to elucidate this toxic action on Escherichia coli (в, Jepp, commune), Serratia marcescens (UK 8) and Aerobacter aerogenes (Hinshelwood).

\section{METHODS}

Organisms. Cultures of Escherichia coli (в, Jepp, commune), Serratia marcescens (UK 8) and Aerobacter aerogenes (Hinshelwood), were grown in a $2 \%$ tryptone medium (pH 7.6) for $16 \mathrm{hr}$ at $37^{\circ}$ by a shake flask technique. Each day suspensions of organisms were prepared by centrifugation from the culture fluid and resuspension

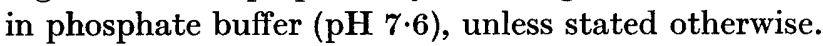

Procedure. The bacterial suspensions were serially diluted in phosphate buffer (pH 7.6) to give the chosen concentration, usually $10^{5}$ colony-forming units $/ \mathrm{ml}$.; $0.5 \mathrm{ml}$. of this suspension was added to $4.5 \mathrm{ml}$. of buffer + polyethylene glycol (PEG) (supplied by L. Light and Co. Ltd., Colnbrook) mixtures of differing PEG compositions, \% (w/v), and were allowed to equilibrate. After a standard time, $1 \mathrm{ml}$. samples were removed and added to $9 \mathrm{ml}$. buffer. The degree of survival in each sample was determined by surface drop plates (Miles \& Misra, 1938) on $1 \%$ tryptone agar or $1 \%$ peptone agar in Petri dishes. After overnight incubation at $37^{\circ}$ the colonies were counted on six plates/sample.

So that more information could be obtained, this procedure was modified to allow a study of the ability of Escherichia coli в to reproduce phage T7, when these $E$. coli organisms were treated with PEG. The technique with phage in aerosol studies was reported previously (Cox \& Baldwin, 1964, 1966). The bacteria, after centrifugation, were resuspended to give a concentration of $3 \times 10^{9} / \mathrm{ml}$. in tryptic meat broth at $37^{\circ}$ 
containing 0.004 M-potassium cyanide added to prevent phage development. After 2 min, to allow the cyanide to take effect, phage $T 7$ was added and the mixture maintained at $37^{\circ}$ for a further period of $10 \mathrm{~min}$. to allow adsorption to occur. After centrifugation, which left unadsorbed phage in the supernatant fluid, the deposited bacteria were resuspended at room temperature in broth containing $0.004 \mathrm{M}$-cyanide, and the centrifugation and resuspension steps were repeated. Dilution in phosphate buffer gave $10^{5}$ phage $T 7$ infected $E$. coli в organisms $/ \mathrm{ml}$. suspension. The procedure then followed that detailed above for non-infected bacteria except that the ability to reproduce phage was determined by plaque formation in $\mathbf{0 . 5} \%$ soft agar in tryptic meat broth layered on $1 \%$ tryptone agar in Petri dishes. As a check on the handling procedure the experiments with infected bacteria were conducted in the presence of Bacillus subtilis var. niger spores, at a concentration similar to that of the $\boldsymbol{E}$. coli $\mathrm{B}$. In this manner the \% plaque formation (and the \% colony formation for a control of non-infected $\boldsymbol{E}$. coli B) could be related to the initial bacterial concentrations allowing for dilution, or to the number of $B$. subtilis var. niger colonies, for the sample under consideration.

The estimates of colony formation of Escherichia coli $\mathbf{B}$, and for plaque formation by phage $\mathbf{T} 7$, initially were conducted with tryptone plates containing crystal violet which inhibited the growth of Bacillus subtilis. This procedure, however, also partially inhibited the growth of $\boldsymbol{E}$. coli B so crystal violet was omitted. The two bacteria were readily differentiated on the control plates, since $\boldsymbol{E}$. coli в formed white colonies and $\boldsymbol{B}$. subtilis var. niger formed orange colonies; the presence of B. subtilis var. niger did not interfere with phage plaque formation.

\section{RESULTS}

\section{Time of contact between polyethylene glycol (PEG) and bacteria}

Results with each of the five organisms in the presence of PEG of molecular weights of 200 and 15,000 at 50\% PEG and 40\% PEG in phosphate buffer (pH 7.6) respectively, were obtained. The curves approximated to a two-stage loss of viability in that an initial rapid decay (0-1 min.) occurred, followed by a much slower decay (1-60 min.). A convenient standard equilibration time of $30 \mathrm{~min}$. was adopted, unless stated otherwise.

\section{Age of bacterial culture}

The influence of age of the bacterial culture was investigated in detail for only the Jepp strain of Escherichia coli. It was found that there was no significant difference in the behaviour of cultures of various ages from $5 \mathrm{hr}$ to 8 days, timed from the end of the 16-hr growth period. This enabled cultures to be prepared weekly. Less detailed studies suggested that the same was true for the other four organisms.

\section{Temperature for equilibration}

The \% survival of a suspension of Escherichia coli Jepp in PEG (1540) and PEG (9000) was determined at $4^{\circ}, 10^{\circ}, 22^{\circ}, 30^{\circ}$ and $37^{\circ}$ as a function of $\%$ PEG made up

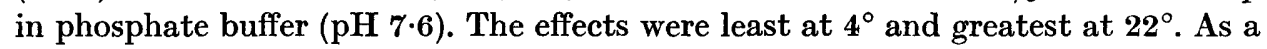
consequence the experimentally convenient temperature of the room $\left(21^{\circ}\right)$ was used for later experiments. 
Bacterial survival as a function of molecular weight and \% PEG

The \% survival (mean of two determinations) of each of the five organisms was studied as a function of \% PEG of molecular weights $200,300,400,600,1540,9000$, 15,000 made up in phosphate buffer ( $\mathrm{pH} \mathrm{7 \cdot 6)}$ Figures 1-4 illustrate the survival observed for PEG 200, 600, 1540, 15,000, respectively, The data were plotted as a function of $\%$ PEG, rather than moles/l., because the molecular weight dependence

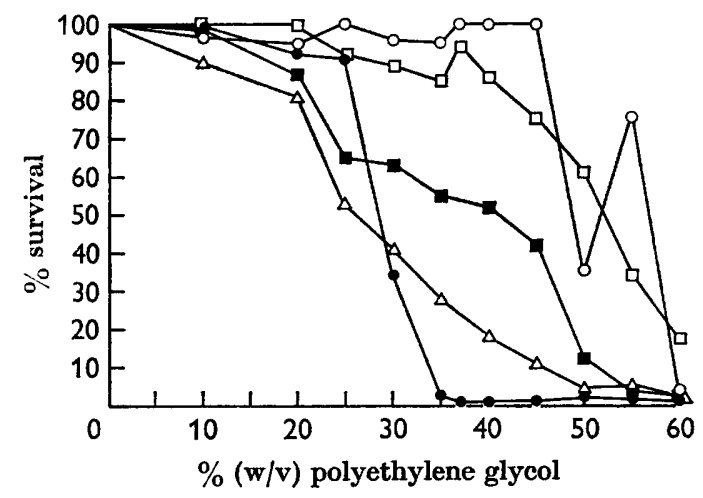

Fig. 1

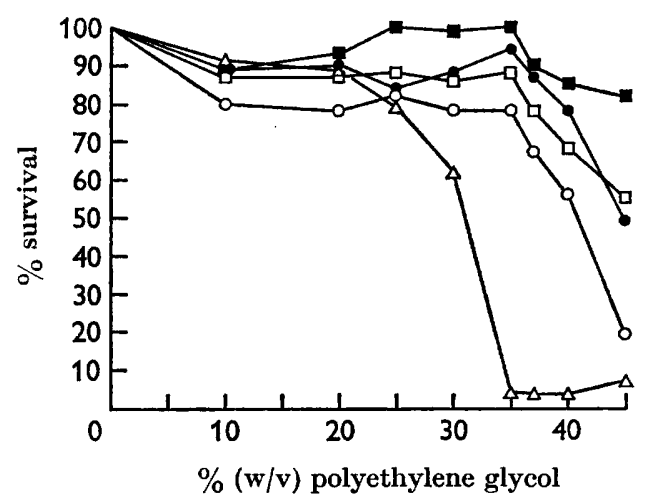

Fig. 3

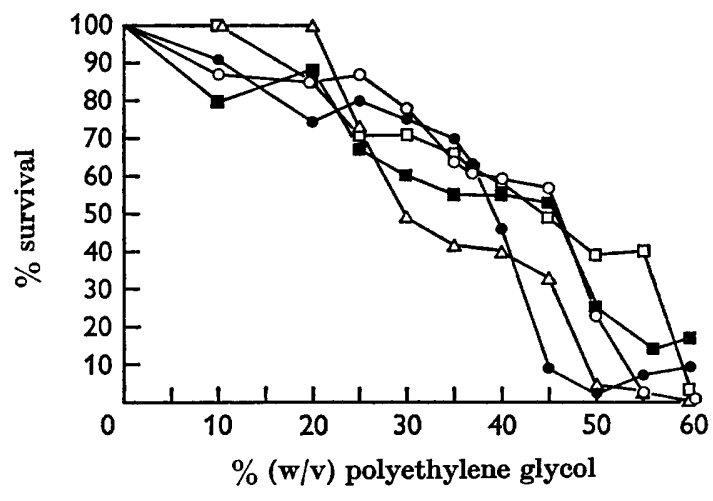

Fig. 2

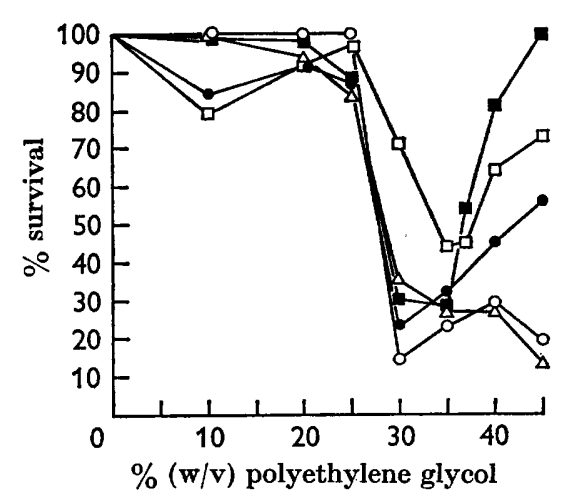

Fig. 4

Figs. 1-4. The survival of bacteria as a function of polyethylene glycol (of different molecular weights) + phosphate buffer mixtures at $21^{\circ}$. Fig. 1. Molecular weight 200 . Fig. 2. Molecular weight 600. Fig. 3. Molecular weight 1540. Fig. 4. Molecular weight 15,000. $\bigcirc$, Escherichia coli в ; $\Delta, E$. coli Jepp; $\square$, E. coli commune; $\square$, Serratia marcescens;

, Aerobacter aerogenes.

was less apparent and virtually disappeared with Escherichia coli Jepp. Results obtained with PEG (300) were similar to those obtained with PEG (200), while with PEG (400) the survivals were intermediate between those using PEG 200 and 600. For the polymer fractions of 9000 and $\mathbf{1 5 , 0 0 0}$, the pattern for the five organisms was similar in that the survival curves all showed a break at about $25 \%$ PEG, followed by a marked change of slope at about 30\% PEG. For lower molecular weight fractions the patterns were less consistent. 


\section{Effects of bacterial concentration}

Escherichia coli (Jepp, B) was studied for the effect of the bacterial concentration. The results for concentrations of $1 \times 10^{9}$ and $1 \times 10^{4}$ bacteria $/ \mathrm{ml}$. were similar and showed no marked effect of concentration over this range.

\section{Clumping behaviour}

Suspensions at a bacterial concentration of $1 \times 10^{9}$ bacteria $/ \mathrm{ml}$. were studied to determine whether the clumping behaviour of the bacteria was modified in the presence of PEG (15,000). With Escherichia coli $\mathrm{B}$ a stable dispersion formed at $30 \%$ PEG, corresponding to the minimum in the survival curve for PEG (15,000) (Fig. 4); at PEG concentrations higher and lower than $30 \%$, flocculation or aggregation (LaMer \& Healy, 1963) occurred, i.e. the state of clumping and \% survival appeared to be related. In PEG (200) a similar relationship was observed between clumping behaviour and \% survival.

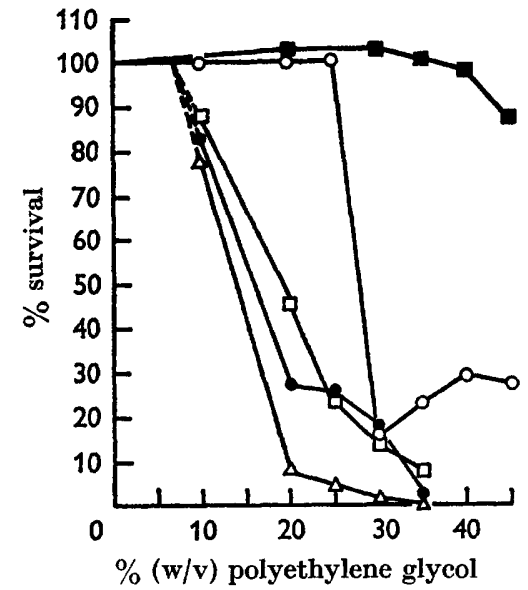

Fig. 5

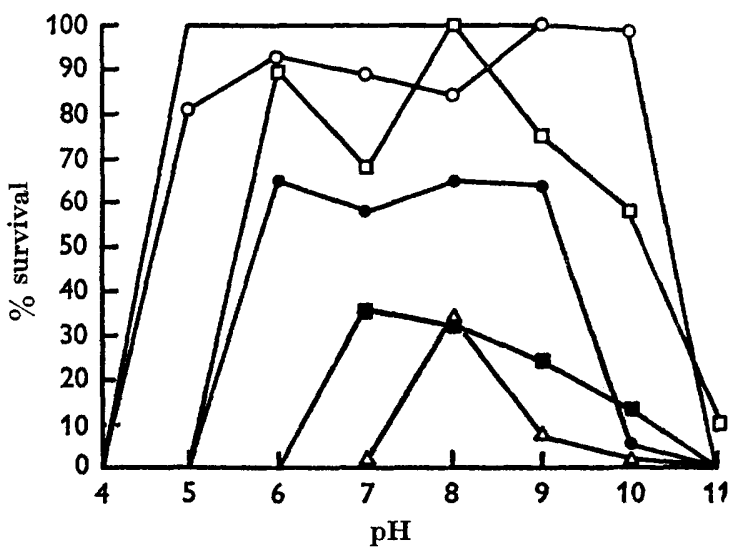

Fig. 6

Fig. 5. The survival of Escherichia col $i \mathrm{~B}$ in polyethylene glycol (molecular weight 15,000) at $21^{\circ}$. $O$, Polyethylene glycol in phosphate buffer; organisms collected in phosphate buffer. $\square$, Polyethylene glycol in tryptic meat broth; organisms collected in tryptic meat broth. $\Delta$, Polyethylene glycol in distilled water; organisms collected in distilled water. Polyethylene glycol in distilled water; organisms collected in phosphate buffer. $\square$, Polyethylene glycol in distilled water; organisms collected in tryptic meat broth.

Fig. 6. Survival of Escherichia coli B in polyethylene glycol + phosphate buffer mixtures as a function of polyethylene glycol $(15,000)$ concentration and $\mathrm{pH}$ value.,$- 0 \% \mathrm{PEG}$; O, $10 \%$ PEG; $\square, 20 \%$ PEG; O, $25 \%$ PEG; , $30 \%$ PEG; $\triangle$, 40\% PEG.

\section{Competitive action of other solutes with PEG}

Protection of Escherichia coli Jepp by sucrose in the presence of PEG (1540) at $30 \%$ PEG, but not at $60 \%$ PEG, was reported previously (Cox, 1965). As an extension of these observations, but with $E$. coli $\mathbf{B}$, solutions of PEG $(15,000)$ in distilled water, phosphate buffer and tryptic meat broth, were studied (Fig. 5). The concentration at which PEG became toxic was dependent upon the presence of other 
solutes. The substantial protection afforded by tryptic meat broth was also markedly apparent for $0.8 \%$ tryptone (or greater), provided that the tryptone was present during contact of the bacteria with PEG (15,000). Contact of bacteria with tryptic meat broth after PEG treatment did not completely prevent the PEG stress. The degree of survival was dependent upon the diluting fluid used for the assay of survival (Fig. 5). The protective action of tryptone, even at $2 \%$, was not marked for PEG (200).

\section{Influence of $\mathrm{pH}$ value}

One of the differences between distilled water, phosphate buffer and tryptic meat broth was the $\mathrm{pH}$ value of these liquids. Figure 6 gives $\%$ survival of Escherichia coli $\mathrm{B}$ as a function of $\mathrm{pH}$ value over the range $\mathrm{pH} 4-11$ and of $\%$ PEG $(15,000)$; it shows that the toxic action of PEG $(15,000)$ was least in the region of $\mathrm{pH}$ 8. The distilled water used for the data of Fig. 5 showed a value of $\mathrm{pH} 5$; the curve at $\mathrm{pH} 5$ in the presence of buffer closely follows the curve for distilled water. The addition to distilled water of a small quantity of buffer salt $(0.001 \mathrm{~m})$ to give pH 8 resulted in behaviour close to that at pH 8 in Fig. 6, i.e. the apparently greater toxicity of PEG $(15,000)$ in distilled water was due to the $\mathrm{pH}$ value rather than to the low ionic strength.

Table 1. Survival in polyethylene glycol of Escherichia coli в and Escherichia coli B + phage T7 complex

$\begin{array}{lccc} & \begin{array}{c}\text { No. of deter- } \\ \text { minations }\end{array} & \begin{array}{c}\text { Arithmetic } \\ \text { mean }\end{array} & \begin{array}{c}\text { Standard } \\ \text { deviation }\end{array} \\ \text { \% survival of control } & 7 & \mathbf{2 6} \cdot 4 & \mathbf{3 \cdot 4} \\ \% \text { lysis* } & \mathbf{5} & \mathbf{9 4 \cdot 2} & \mathbf{8 \cdot 5} \\ \% \text { lysis } \dagger & 4 & \mathbf{5 6} \cdot \mathbf{7} & \mathbf{3 \cdot 8} \\ \text { * On non-dyed agar plates. } & \dagger \text { On agar plates + crystal violet. }\end{array}$

The Escherichia coli $\boldsymbol{B}+$ phage $\mathbf{T} 7$ complex

Escherichia coli $\mathrm{B}$ infected with phage $\mathbf{T} 7$ in an undeveloped state were prepared by the method described. The results of subjecting these bacteria and the noninfected controls to $30 \%$ PEG $(\mathbf{1 5 , 0 0 0 )}$ for $10 \mathrm{~min}$. are given in Table 1 . The data included results for culture ages of from $16 \mathrm{hr}$ to 7 days, and for phage:bacteria ratios of $1 \cdot 2,1 \cdot 5,3,7$ and $30: 1$. It is concluded that the action of PEG $(15,000)$ upon $E$. coli B, did not affect those reactions involved in phage reproduction; however, the combined action of PEG $(15,000)$ and crystal violet partially inhibited phage growth and lysis. In the terms used previously (Cox \& Baldwin, 1964, 1966) the action of PEG $(\mathbf{1 5 , 0 0 0 )}$ upon $E$. coli B is to prevent $E$. coli B reproduction.

The result of subjecting the Escherichia coli $\mathrm{B}$ infected with phage $\mathrm{T} 7$ and the noninfected controls to PEG (200) at $60 \%$ for $10 \mathrm{~min}$. was that lysis and survival values of the order of $12 \%$ were obtained. This suggests that PEG (200) influenced the $E$. coli B phage productive capacity (Cox \& Baldwin, 1964, 1966). i.e. the action of high and low molecular weight PEG would seem to be at different loci of action. 


\section{DISCUSSION}

The use of phage showed that the reproductive capacity of Escherichia coli в was impaired by polyethylene glycol (PEG; 15,000). Since the latter penetrates the cell wall very slowly, if at all, and does not penetrate the cytoplasm, both the cell wall and cell division seem to be implicated as at least one locus of action of PEG $(15,000)$. PEG of molecular weight 200, being able to pass through the cell wall but not the cytoplasmic membrane, may be able to operate at a second locus of action concerned with $E$. coli в phage productive capacity, but which cannot be reached and preserved by tryptone. The clumping behaviour of bacteria in PEG (15,000 and 200) also suggests that changes in the cell surface occur, since clumping behaviour depends upon the interactions of cell-wall surfaces. It is perhaps a coincidence that the stable suspension forms at the \% PEG, which gives a minimum in the survival curve (Fig. 1, 4), although the action of tryptic meat broth is both to prevent the action of PEG $(15,000)$ and also to prevent dispersion.

Since the data exhibit a more regular pattern when related to a $\%$ rather than a molar concentration scale, the concentration of the repeat unit of the PEG may be the important factor. Percentage PEG values are approximately converted to moles repeat unit/l. by multiplying the \% value by a factor of $\mathbf{0 \cdot 2 2}$. Of the five organisms, Escherichia coli Jepp showed the least dependence upon molecular weight, although any such relationship may be fortuitous, since it was shown that PEG of low and high molecular weight had different actions. Other substances (from the Dow Chemical Co. Michigan) such as polypropylene glycol (400); Ambiflo H7, H52, H438 (300, 1000, 3500 respectively) a dialkoxyether of polyoxyalkylene glycol; Hyprin GP30 (266) a hydroxypropyl glycerol; polyglycol 15-200 (2600) $\mathrm{CH}_{2} \mathrm{OR}_{n} \mathrm{H}$.CHOR $\mathrm{H}_{n} \mathrm{CH}_{2} \mathrm{OR}_{n} \mathrm{H}$, where $\mathrm{R}$ is $\mathrm{C}_{2} \mathrm{H}_{4} \mathrm{O}-\mathrm{C}_{3} \mathrm{H}_{6} \mathrm{O}$, behaved somewhat like PEG. Thus the phenomenon does not appear to be specific with regard to the nature of the agent.

The action of PEG may involve its adsorption; it was suggested (Cox, 1965) that the wetting properties of the bacterial surface might be effected. However, since phage $T 7$ reproduction was not impaired by PEG $(15,000)$ a change of wetting properties is not a likely explanation. Polymer phase separations in which a mixture of polymers forms a single homogeneous phase or separates into phases depending upon concentration, etc., may be pertinent. Such systems have been studied by Dervichian (1954), by Hyde, Langbridge \& Lawrence (1954), by Albertsson (1960) and by Polson et al. (1964). Polson et al. found that with mixtures of protein + polyvinyl alcohol type, precipitation and denaturation of protein occurred, whereas mixtures of protein +dextran or + PEG resulted in phase separation without denaturation. The protein precipitation was dependent upon protein concentration, temperature, $\mathrm{pH}$ value and PEG concentration; this behaviour is similar to that described in the present paper.

The protective action of sucrose and perhaps protein is consistent with phase separation since multiplicity of hydroxyl groups produces marked increases in solubility (Hyde et al. 1954). The effect of $\mathrm{pH}$ value is consistent also with phase separation of an ionic polymer, since the solubility of such a polymer is related to its charge and this will change with the $\mathrm{pH}$ value. An understanding of the influence of temperature in terms of phase separation would require knowledge of the phase 
diagram, since temperature changes can cause dramatic effects (Albertsson, 1960), while the marked recovery in viability for PEG of high molecular weight (Fig. 4) is not contrary to phase separation (Hyde et al. 1954). It therefore seems possible that the action of PEG might be explained through the phase separation of groups which normally would be in solution and attached to the cell membranes. Such an action would then have to cause a detrimental change in the structure of the cell membranes.

The author thanks Mr I. H. Silver for his interest in this work and thanks Mr M. C. Aireton for technical assistance.

\section{REFERENCES}

Albertsson, Per-Åke. (1960). Partition of cell particles and macromolecules. New York: John Wiley and Sons; Stockholm: Almqvist and Wiksell.

Cox, C. S. (1965). Protecting agents and their mode of action. 1st Int. Symp. on Aerobiology, p. 345. Published by Naval Biological Laboratory, Naval Supply Centre, Oakland, California.

Cox, C. S. \& Baldwin, F. (1964). A method for investigating the cause of death of airborne bacteria. Nature, Lond. 202, 1135.

Cox, C. S. \& Baldwin, F. (1966). The use of phage to study causes of loss of viability of Escherichia coli in aerosols. J. gen. Microbiol. 44, 15.

Dervichian, D. G. (1954). A comparative study of the flocculation and coacervation of different systems. Discuss. Faraday Soc. 18, 231.

Hyde, A. J., Langbridge, D. M. \& Lawrence, A. S. C. (1954). Soap plus water plus amphiphile systems. Discuss. Faraday Soc. 18, 239.

LAMER, V. K. \& HEaly, T. W. (1963). Adsorption-flocculation reactions of macromolecules at the solid-liquid interface. Rev. pure appl. Chem. 13, 112.

Miles, A. A. \& Misra, S. S. (1938). Estimation of the bactericidal power of blood. J. Hyg. Camb. 38, 732.

Polson, A., Potgieter, G. M., Largier, J. F., Mears, G. E. F. \& Joubert, F. J. (1964). Fractionation of protein mixtures by linear polymers of high molecular weight. Biochim. biophys. Acta 82, 463. 